\title{
Desain Interior Bus Tingkat Sleeper Class
}

\author{
Rizal Firmansyah,,$^{*}$ Hamdan Bahalwan ${ }^{2}$ \\ ${ }^{1,2}$ Jurusan Desain Produk, Institut Teknologi Adhi Tama Surabaya, Surabaya, Indonesia
}

\begin{tabular}{|l|l|l|}
\hline Received: September 2021 & Acepted: September 2021 & Published: October 2021 \\
\hline
\end{tabular}

\begin{abstract}
Sleeper class bus belongs to the highest class in the inter-city inter-province bus services. However, sleeper class still has weaknesses such as narrow movement spaces and piled configuration. The facility of sleeper class has not been available at all stations of inter-city inter-province bus yet. Therefore, the researcher developed innovation in the interior design of sleeper class of inter-city inter-province bus by implementing sleeper class to the whole interior. By mixed method, this research combined qualitative and quantitative methods. Besides, it added several design analyses on the activity, need, color, shape, system, technology, safety, bus, symbol, ergonomics, and anthropometry. The ultimate result was a product employing the modern and exclusive concepts. This sleeper class bus consists of two floors namely up floor and down floor equipped with chairs that can adjust the users' needs, whereas the configuration applies 1-1 to keep privacy. The materials being used had been adapted with the material analysis, while the colors of product were taken from the color analysis. The sizes of chair, cabin, and interior complies with the anthropometry of Indonesian people and the regulation of double decker bus.
\end{abstract}

Key words: bus, interior, sleeper class, transportation

\begin{abstract}
Abstrak
Bus kelas sleeper class yang merupakan kelas tertinggi dalam pelayanan bus antar kota antar provinsi. Namun sleeper class masih memiliki kekurangan seperti ruang gerak yang kurang luas serta konfigurasi yang bertumpuk, juga fasilitas sleeper class belum terdapat di seluruh bis antar kota antar provinsi. Maka peneliti membuat terobosan inovasi pada Desain interior bus tingkat sleeper class antar kota antar provinsi dengan menerapkan seluruh interior menjadi sleeper class. Metode penelitian yang di gunakan pada penelitian ini menggunakan mix method kuantitatif dan kualitatif, kemudian ditambahkan dengan analisis desain yang mencangkup analisis, aktivitas, analisis kebutuhan, analisis warna, analalisi bentuk, analisis sistem, analisis teknologi, analisis keamanan, analisis bus, simbol, analisis ergonomi dan antropometri Untuk produk yang dihasilkan adalah sebuah produk yang akan menerapkan konsep modern dan ekslusif, dalam produk bus slepeer class ini terdapat dua lantai yaitu lantai atas dan lantai bawah yang di lengkapi kursi yang dapat disesuaikan dengan kebutuhan pengguna dan konfigurasi yang di terapkan 1-1 untuk menjaga privasi, menggunakan material yang di sesuaikan dengan analisis material. Warna yang di terapkan pada produk ini mengambil dari analisis warna dan juga ukuran kursi ,kabin dan interior menyesuaika antropometri orang indonesia dan ukuran regulasi dari bus tingkat.
\end{abstract}

Kata kunci: Bus, Interior, Sleeper class, Transportasi

\footnotetext{
* Corresponding author : ricaelfiermansyah@gmail.com .
} 


\section{Pendahuluan}

Bus mampu menjangkau kota - kota kecil yang belum bisa terjangkau transportasi lain seperti kereta dan pesawat. Sehingga penumpang di kota - kota kecil masih memiliki akses naik bus yang lebih mudah. Bus sebagai penyedia layanan antar kota antar provinsi tentunya harus memperhatikan kebutuhan dan keinginan konsumen dalam pelayanan. salah satu bentuk pelayanan yang di berikan bus adalah seat sleeper class yang hanya terdapat di beberapa unit bus saja. Sleeper class merupakan kelas tertinggi dalam pelayanan bus antar kota antar provinsi, Memiliki konfigurasi 1-1 dengan kursi yang bisa direbahkan dengan kabin privasi tersendiri. kabin bus dibuat khusus seperti kabin personal di pesawat, sleeper class memiliki seat atau tempat tidur yang berasal dari kursi penumpang dengan sandaran kaki panjang serta sandaran punggung yang bisa direbahkan sampai 150 derajat. [1] dimana kelas ini menyediakan fasilitas seperti seat yang di gunakan menggunakan material yang memanjakan penumpang yang di lengkapi entertaiment system sehingga penumpang dapat merasakan perjalan dengan posisi tiduran dan duduk seperti di kamar sendiri.

Akses mudah yang di berikan perusahaan otobis dengan sleeper class masih memiliki kekurangan yaitu sempit ruang gerak pada cabin, untuk Suites class menggunakan seat yang bertumpuk sehingga sulit untuk akses masuk bagi masyarakat lanjut usia, juga sering terjadi masalah pada bau kaki karena tempat duduk yang bersusun atas dan bawah pastinya untuk penumpang atas memerlukan tangga untuk naik dan saat posisi naik maka penumpang akain naik tangga yang dekat dengan posisi kepala. Sedikitnya bus yang menggunakan fasilitas sleeper, bus dengan fasilitas sleeper biasanya melakukan perjalanan paling singkat 8 jam, sehingga penumpang membutuhkan sebuah tempat yang mampu memberikan rasa aman dan nyaman saat perjalanan.

Maka dari itu peneliti akan mendesain interior bus tingkat antar kota antar provinsi kelas sleeper class ekslusif sebagai alternatif berpergian selain pesawat terbang dengan rute minimal 800 Kilometer, yang menerapkan seluruh interior dengan konfigurasi 1-1 menggunakan fasilitas sleeper class yaitu penumpang bisa menikmati perjalanan sambil tidur dengan privasi yang tinggi dilengkapi suspensi udara untuk menambah kenyamanan saat perjalanan.Sedangkan artikel yang berbentuk resensi buku, biografi, atau feature yang berasal dari pemikiran-pemikiran kritis, dapat disesuaikan dalam hal pengaturan sub-judulnya. Anda diharapkan selalu mengontrol format tulisan anda pada menu paragraph.

\section{Metode penelitian}

Penelitian ini menggunakan mix method yaitu penelitian kuantitatif dan kualitatif. Penelitian campuran merupakan prosedur untuk mengumpulkan, menganalisis dan mencampur metode kuantitatif dan kualitatif dalam satu penelitian atau serangkaian penelitian untuk memahami permasalahan penelitian Penelitian campuran adalah kelas studi penelitian di mana peneliti mencampur atau menggabungkan kuantitatif dan pendekatan penelitian kualitatif teknik dalam studi penelitian tunggal. Objek penelitian yakni bus tingkat rosalia indah dengan rute Malang Jakarta dan bus tingkat Harapan jaya dengan rute Surabaya Jakarta. Wawancara kepada 1.Penumpang bus sleeper, data yang didapat adalah material dan fasilitas yang ada pada bus sleeper 2.Supir bus sleeper, data yang didapat adalah keluhan kekurangan dan kelebihan bus sleeper. Kuisoner dilakukan sebagai penentuan visual desain bus sleeper, pengambilan data kuisoner dilakukan dengan cara membagikan kuisoner melalui google form. Kuisoner dibagikan ke 35 orang, data yang didapat adalah mengenai penentuan desain final yang dipilih responden. Dokumentasi Pengambilan data dengan cara mendokumentasikan setiap bagian dari penelitian yang dilakukan saat pencarian data yang akan dilakukan di bus sleeper. Kemudian melakukan analisis kebutuhan, analisis aktivitas, analisis bentuk, analisis warna, analisis sistem, analisis penempatan, analisis teknologi, analisis keamanan, analisis material, analisis Bus Double deck, analisis ergonomi dan analisis antropometri Penelitian ini berguna untuk menggambarkan fenomena yang kompleks, dapat melihat perbandingan antar kasus, dan penelitian ini mampu menganalisis hasil gabungan dari penelitian kuantitatif dan kualitatif sehingga data akan semakin jelas dan saling melengkapi. 
Rizal Firmansyah, Hamdan Bahalwan Desain Interior Bus Tingkat Sleeper Class

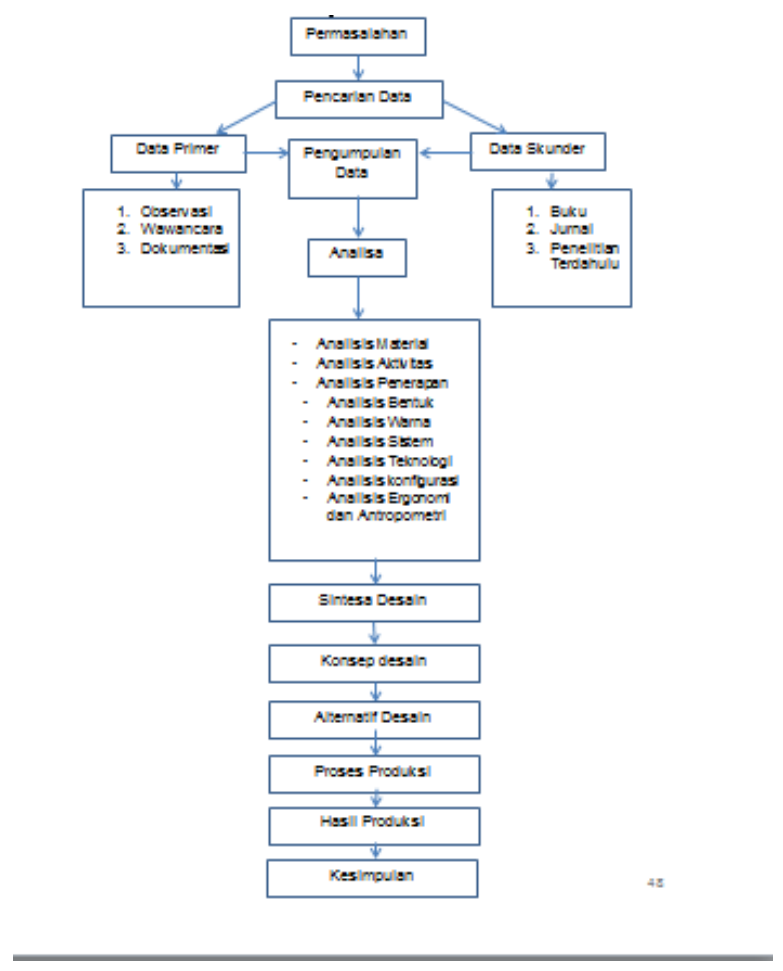

Gambar 1 Diagram Penelitian (Sumber: dokumen pribadi)

\section{Analisis}

\subsection{Analisis Aktivitas}

Berdasarkan aktivitas penumpang di lapangan bahwa penumpang bus tingkat membutuhkan pegangan tangan,pintu tengah khusus penumpang, electric seat, usb charger, AVOD dan seat sleeper class untuk memenuhi aktivitas penumpang

\subsection{Analisis Kebutuhan}

Berdasarkan pada studi aktivitas menunjukkan beberapa kebutuhan yang diperlukan yaitu menerapkan tirai pada setiap sleeper class untuk membantu penumpang agar sinar matahari tidak langsung masuk kedalam kabin senggia mengubah suhu pada cabin, kemudian menerapkan meja lipat pada setiap seat agar penumpang dapat mudah untuk menikmati fasilitas seperti makan atau snack yang di berikan oleh crew bus.

\subsection{Analisis Bentuk}

Berdasarkan di lapangan dan mengacu pada tinjauan tentang psikologi bentuk [2], bentuk yang akan diterapkan pada interior bus menggunakan bentuk persegi panjang pada ruang cabin interior,cabin sleeper class, konsole samping dan bentuk hexagonal pada lampu cabin, penerapan bentuk pada kursi menggunakan bentuk persegi panjang pada bagian sandaran kaki, kemudan pesegi pada bagian duduk dan combinasi bentuk persegi panjang dan lingkaran padana sandaran tangan, headrest dan sandaran punggung

\section{4. Analisis Warna}

Adapun penerapan warna interior bus mengacu pada tinjauan psikologi bentuk [3] adalah warna biru, hitam putih. Warna biru di karenakan untuk memberi kesan rileks, menenangkan dan dingin agar penumpang bisa mendapatkan ketenangan dan rileks saat melakukan perjalanan. Untuk warna putih di pilih karena dalam 
penerapan interior kendaraan warna putih membawa pengguna masuk dalam kesan bersih. Untuk warna hitam di pilih karena warna hitam digunakan sebagai warna netral dan sebagai dominan pada interior

\section{5. Analisis Sistem}

Sistem yang akan di terapkan pada interior bus sleeper class menggunakan electric seat pada kursi penumpang sehingga dapat mempermudah penumpang mengatur trmpat duduk dan sistem remot control pada AVOD di perlukan untuk di nikmati penumpang selama perjalanan.

\section{6. Analisis Penempatan}

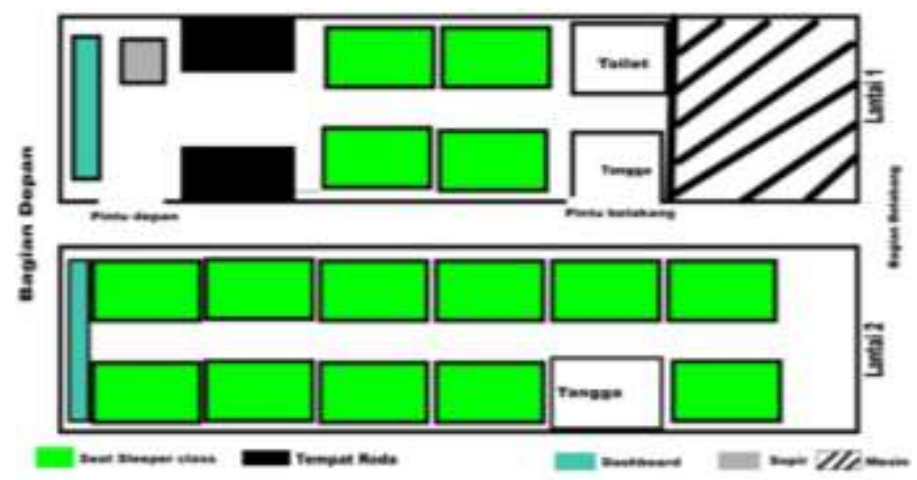

Gambar 2 Penempatas kursi bus (Sumber: dokumen pribadi)

hasil analisis penempatan mengacu pada literatur studi konfigurasi kursi penumpang, menggunakan penempatan no 2 menggunakan susunan lurus dengan Kotak hijau yang disajikan dalam gambar digunakan untuk seat sleeper class berjumlah 15 seat, sedangkan gambar bewarna biru muda digunakan untuk dashboard dan berwarna abu-abu letak supir

\section{7.Analisis Teknologi}

teknologi yang akan di terapkan pada bus sleeper class adalah suspensi udara, AVOD, wifi dan Usb Charger

\section{8.Analisis Keamanan}

Penerapan keamaan dalam bus tingkat sleeper class mengacu pada peraturan regulasi kendaraan indonesia dan literatur keamanan akan menggunakan seat belt pada setiap seat, menerapkan alat pemecah kaca pada setiap seat bus, kemudian menerapakan penunjuk pintu darurat yang bisa menyala dalam gelap pada bus

\section{8.Analisis Material}

Penerapan material mengacu pada tinjauan material sehingga pada lantai bus menggunakan material vinil karena secara penampilan, bahan vinyl memiliki warna dan bentuk yang bagus dan terkesan mewah [4], besi yang akan di terapkan pada rangka interior bus, alumunium dan kayu yang akan di terapkan pada cabin sleeper class karena kayu karena keawetannya dan daya tahannya terhadap perubahan cuaca [5] dan plastik di gunakan pada seluruh interior bus. Kemudian untuk kursi menggunakkan kombinasi material kulit sintetis dan kain suet agar menambah kesan modern.

\section{9.Analisis Bus Double Deck}

analisa bodi bus double deck yang cocok di gunakan untuk bus tingkat sleeper class adalah SR2 XDD karena body yang anti limbung serta dpat di gunakan pada chassis yang lebih panjan. 
Rizal Firmansyah, Hamdan Bahalwan Desain Interior Bus Tingkat Sleeper Class

\section{11.Analisis Ergonomi}

Ergonomi AVOD (Audio Video On Demand) untuk mengukur jarak melihat monitor yang baik maka di dapat sebagai berikut bahwa jarak paling aman antara mata dengan layar monitor yang baik yaitu 18-24 inch atau 46$61 \mathrm{~cm}$ [6], Untuk Ketinggian pada foot step yang akan di terapkan menggunakan tinggi $15 \mathrm{~cm}$ untuk mempermudah siapa saja untuk naik kedalam kendaraan [7].

\section{12.Analisis Antropometri}

Analisa Antropometri berdasarkan data literatur antropometri indonesia Analisa dimensi cabin sleeper Dimensi cabin sleeper class menggunakan dimensi persentil ke 50\% data antropometri orang indonesia Panjang $200 \mathrm{~cm}$ Lebar $90 \mathrm{~cm}$ Tinggi $120 \mathrm{~cm}$ Analisa Ukuran kursi dimensi ukuran kursi menggunakan dimensi persentil ke-50\% dari data antropometri orang indonesia umur $17-47$ thn Dimensi sandaran punggung Tinggi dalam posisi duduk $78.1 \mathrm{cmLebar}$ bahu atas $=31.32 \mathrm{~cm}$ Jadi untuk dimensi sandaran punggung dan head rest adalah $78.1 \times 31.32$ cmDimensi dudukan kursi Panjang Polipetal $39.88 \mathrm{~cm}$ Lebar pinggul $32.32 \mathrm{~cm}$ Jadi untuk dimensi dudukan kursi adalah 39.88 x $32.32 \mathrm{~cm}$ Dimensi sandaran kaki Tinggi popliteal 40,08 cm Lebar pinggul 32,32 cm Jadi untuk dimensi sandaran kaki adalah 40,08 x 32,32 cm Sandaran Tangan Lebar tangan $9.43 \mathrm{~cm}$ Panjang lengan bawah $40.53 \mathrm{~cm}$ Jadi untuk dimensi sandaran tangan $=9.43 \times 40.53 \mathrm{~cm}$ Anlalisa: jadi untuk dimensi pada kursi penumpang bus sleeperclass adalah Lebar: $41 \mathrm{~cm}$ x tinggi $120 \mathrm{~cm}$ x panjang $60 \mathrm{~cm}$.

\section{13.Konsep Desain}

Konsep desain yang akan di terapkan pada Desain Interior bus tingkat sleeper class adalah konsep interior Ekslusif dan Modern Minimalis. Deskripsi Minimalis modern adalah desain yang lebih efisien dan efektif melalui kesederhanaan dalam bentuk, ruang, material, detil dan warna.

\section{14.Alternatif Desain}
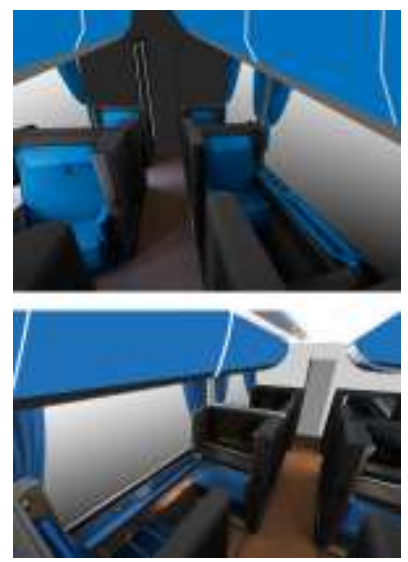

Gambar 3. Alternatif desain 1
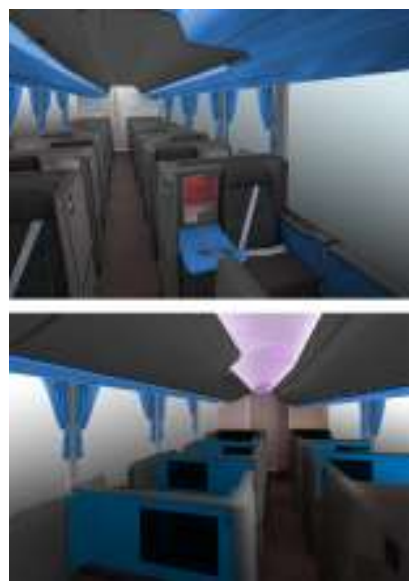

Gambar 5. Alternatif desain 3

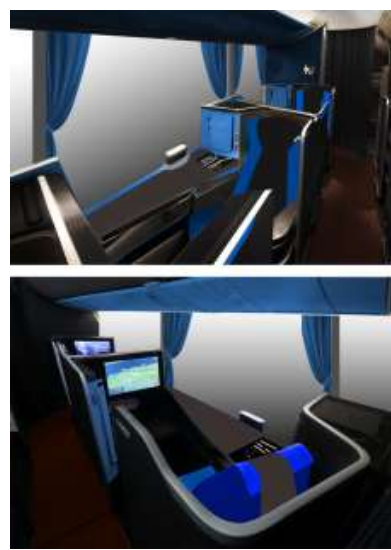

Gambar 4. Alternatif desain 2

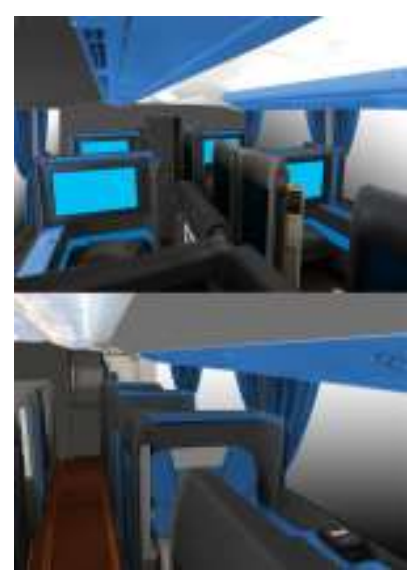

Gambar 6. Alternatif desain 4

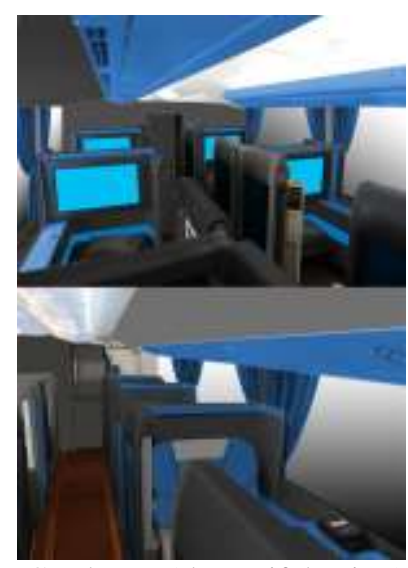

Gambar 7. Alternatif desain 5 


\section{15. DesainTerpilih}
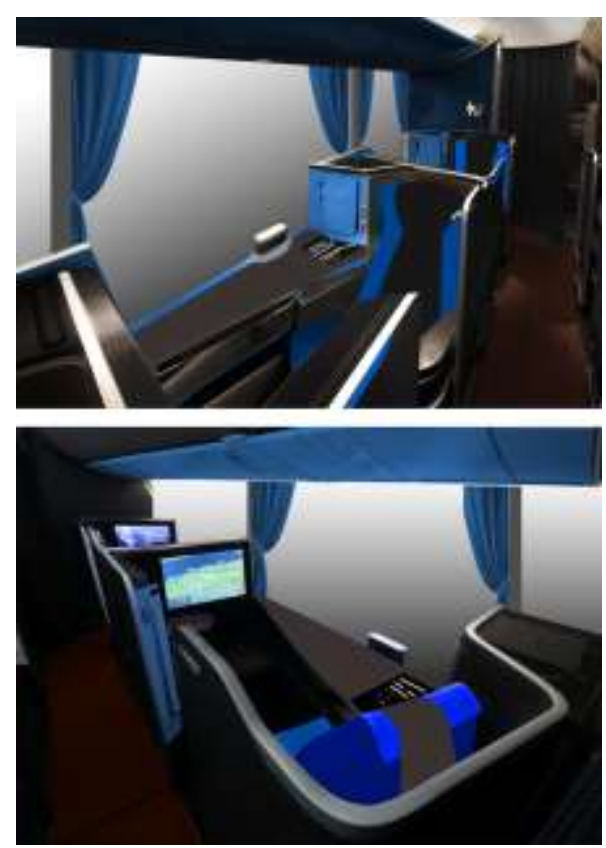

Gambar 8 Desain Terpilih (Sumber: dokumen pribadi)

Pemilihan desain terpilih berdsarkan visual kuisioner yang di berikan kepada 35 pengguna bus

\section{Kesimpulan}

Kesimpulan dari produk Redesain interior bus tingkat sleeper class antar kota antar provinsi ditujukan untuk membantu masyarakat yang ingin menikmati kelas sleeper class dengan ekslusif ,dengan memberikan fasilitas dan ruang yang lega juga konfigurasi yang nyaman untuk menikmati perjalanan sambil tidur di dalam bis seperti kamar sendiri sehingga penumpang tidak merasa lelah walaupun perjalan jauh sekalipun 
Rizal Firmansyah, Hamdan Bahalwan Desain Interior Bus Tingkat Sleeper Class

\section{Daftar pustaka}

1. Kompas. Ketahui Perbedaan Bus Suites Class dengan Sleeper Seat. 2020 [cited 20209 April]; Available from: https://otomotif.kompas.com/read/2020/03/19/082200715/ketahui-perbedaan-bus-suites-class-dengan-sleeper-seat.

2. Ichi.pro. Ichi.pro. (2019). Psikologi bentuk dalam Desain: bagaimana bentuk yang berbeda dapat mempengaruhi perilaku orang. 2019 [cited 2019; Available from: Www.Ichi.Pro. https://ichi.pro/id/psikologi-bentuk-dalamdesain-bagaimana-bentuk-yang-berbeda-dapat-mempengaruhi-perilaku-orang-21761760742942.

3. Epsikologi. Psikologi Warna: Pengertian, Teori dan Manfaatnya Untuk Bisnis. 2019; Available from: Www.Epsikologi.Com. https://epsikologi.com/psikologi-warna/.

4. $\quad$ vinylpro. Apa itu vinyl? Mengenal lebih jauh si kulit sintetis. 2019; Available from: Www.Vinylpro.Id. https://vinylpro.id/apa-itu-vinyl/.

5. tentangkayu. Kayu Jati (Tectona Grandis). 2019; Available from: Www.Tentangkayu.Com. http://www.tentangkayu.com/2008/12/kayu-jati-tectona-grandis.html.

6. H.N., S. Berapa Jarak Menonton Televisi yang Tepat? 2019 [cited 2019; Available from: Www.Klikdokter.Com. https://www.klikdokter.com/info-sehat/read/3628583/berapa-jarak-menonton-televisi-yang-tepat.

7. Kompas. Berapa Jarak Antar Anak Tangga yang Ideal? Berikut Penjelasannya. 2021; Available from: Www.Kompas.Com. https://www.kompas.com/homey/read/2021/01/02/140500176/berapa-jarak-antar-anak-tanggayang-ideal-berikut-penjelasannya. 